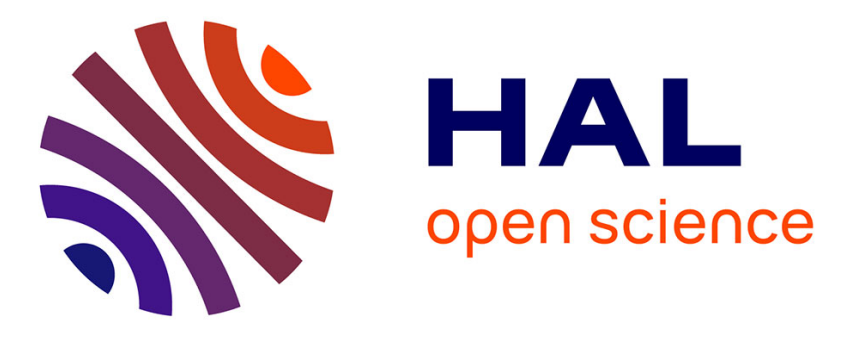

\title{
A New Decision Support Tool for Dynamic Risks Analysis in Collaborative Networks
}

Afshin Jamshidi, Samira Abbasgholizadeh Rahimi, Daoud Ait-Kadi, Angel Ruiz

\section{To cite this version:}

Afshin Jamshidi, Samira Abbasgholizadeh Rahimi, Daoud Ait-Kadi, Angel Ruiz. A New Decision Support Tool for Dynamic Risks Analysis in Collaborative Networks. 16th Working Conference on Virtual Enterprises (PROVE), Oct 2015, Albi, France. pp.53-62, 10.1007/978-3-319-24141-8_5 . hal01437930

\section{HAL Id: hal-01437930 \\ https://hal.inria.fr/hal-01437930}

Submitted on 17 Jan 2017

HAL is a multi-disciplinary open access archive for the deposit and dissemination of scientific research documents, whether they are published or not. The documents may come from teaching and research institutions in France or abroad, or from public or private research centers.
L'archive ouverte pluridisciplinaire HAL, est destinée au dépôt et à la diffusion de documents scientifiques de niveau recherche, publiés ou non, émanant des établissements d'enseignement et de recherche français ou étrangers, des laboratoires publics ou privés. 


\title{
A New Decision Support Tool for Dynamic Risks Analysis in Collaborative Networks
}

\author{
Afshin Jamshidi ${ }^{1}$, Samira Abbasgholizadeh Rahimi ${ }^{2}$, Daoud Ait-kadi ${ }^{3}$ and Angel Ruiz ${ }^{4}$ \\ 1,2,3 Department of Mechanical Engineering, Université laval, Quebec, Canada \\ ${ }^{4}$ Department of Operations and Decision Systems, Quebec, Canada \\ Afshin.jamshidi.1@ulaval.ca
}

\begin{abstract}
Collaborative networks are complex systems and consist of many factors with dependencies among them. Although the number of collaborative networks such as advanced supply chains or virtual organizations/laboratories/e-science is growing and their significance is increasing in the world, many of them are unsuccessful. In addition, very little attention has been paid to the risk analysis of collaborative networks by considering the dependencies among risk factors. So, the precise risks analysis associated with collaborative networks projects is crucial to attain a satisfactory performance. To address this, we are proposing an advanced decision support tool called "Fuzzy Cognitive Maps" (FCM) which can deal with risks of such complicated systems by considering the interrelationships between factors. FCM states the behaviour of complex systems accurately and illustrate any complex environment based on the experts' perceptions and by graphical representations. It is able to consider uncertainties, imprecise information, the interactions between risk factors, Information scarcity, and several decision maker's opinions. FCM is not only able to evaluate risks more precisely in collaborative networks, but also it could be applied in different decision makings problems related to collaborative networks such as partner selection and forecasting behaviors, policy analysis, modeling collaboration preparedness assessment, etc. Hence, the proposed tool would help practitioners to manage collaborative network risks and decision making problems effectively and proactively.
\end{abstract}

Keywords: Risks analysis, Collaborative networks, Fuzzy cognitive maps, virtual enterprises, Expert knowledge.

\section{Introduction}

Collaborative networks (CNs) such as virtual organizations, dynamic supply chains, professional virtual communities, collaborative virtual laboratories, etc. are complex systems associated with uncertainties in dynamic business environments. This uncertainty and complexity could lead to critical risks which could influence on the enterprises' performance. According to Munyon \& Perryman [1], failure rate of alliances are estimated between $60 \%$ and $70 \%$. Risk evaluation of CNs is a complex and critical task 
since several tangible and intangible risk factors should be considered in this process. In addition, there are always some dependencies among risks that can influence each other mutually and these dependencies make the evaluation process more complex and challenging. Therefore, an effective method for evaluating the risks is fundamental and essential. In recent decade, many problems related to CNs such as partner selection [2] [3] [4], modeling collaboration preparedness assessment [5], etc. have been investigated. However, very little attention has been paid to the risk analysis of collaborative networks by considering the dependencies among risk factors [6] [7].

Li \& Liao [6] identified all possible risks which could influence on the operation of alliance and measured their priority numbers using three criteria; probability of risk, severity of risk and risk detection number. Das and Teng [8] developed a risk perception model. The model consists of the following components: the antecedents of risk perception, relational risk and performance risk, risk perception and structural preference, and the resolution of preferences. Ip et al. [9] described and modeled a risk-based partner selection method by taking into account risk of failure, due date and the precedence of sub-project. In addition, a rule-based genetic algorithm with embedded project scheduling was proposed to solve the problem. Huang et al. [10] developed a risk management model for virtual enterprises (VE) and presented a tabu search algorithm by considering uncertainties in experts' opinions. Huang et al. [11] proposed a two level Distributed Decision Making (DDM) model for the risk management of dynamic alliance. A Particle Swarm Optimization (PSO) algorithm is used to solve the resulting optimization problem. Their proposed model improves the description of the relationship between the owner and the partners.

However, research about the risk assessment of $\mathrm{CNs}$ by considering the interrelationships among risks factors and forecasting the impact of each risk on the other risks don't exist in the literature of CNs and further research in this field is required. Considering the interdependencies among risks could lead to more accurate risk assessment to enterprises. In addition, during the risk assessment process, there are lots of uncertainties and imprecise information associated with experts opinions that should be taken into account. Recently, Zhou and Lu [7] presented a methodology for choosing a coalition partner using Fuzzy Analytic Network Process (FANP) and by considering the interaction and feedback relationships between risk factors. Although ANP is able to consider interdependencies among factors, it has some disadvantages. Sometimes it is not easy even for experts to compare the importance of a factor to another [12]. In addition, different structures could lead to the different rankings and it is usually difficult for experts to provide the true relationship structure by taking into account several factors. Moreover, ANP is time-consuming due to the large number of pair-wise comparisons needed for comparing the risk factors.

Therefore, this paper deals with risk assessment of CNs as the most important phase of risk management, and proposes an advanced decision support tool called "FCM" to overcome the shortcomings of current risk evaluation tools applied in CNs. FCM is a useful tool that states and evaluate the dynamic behaviour of complex systems by 
considering the interrelationships among factors [13]. It considers the uncertainties and imprecise information by using linguistic variables. Hence, expert perception is considered in the model more precisely. Moreover, FCM can even be used when the information is scarce. This tool recently has been applied successfully in evaluating risks in complex and critical environments such as Enterprise Resource Planning (ERP) maintenance [14] [15] and IT projects [16], and therefore we think it has a good potential to be applied in complex CNs for evaluating risks and forecasting the impact of each risk. The reminder of this paper is organized as follows. Section 2 introduces the FCM fundamentals. Section 3 explains the proposed tool with an example related to risk evolution in dynamic alliance and conclusions are drawn in Section 4.

\section{FCM Fundamentals}

Fuzzy Cognitive Map (FCM) was originally introduced by Kosko in 1986 [17] as a tool for modeling complex systems, able to consider dependencies among different criteria and based on experience and knowledge of experts. In the last decade, FCM has been widely employed in the variety of applications such as, decision analysis, engineering science, political decision making, failure detection, process control, and medical diagnosis [18]. More information about the different applications of FCM are available in [19] and [20] books.

FCMs are a combination of fuzzy logic and neural networks and are able to represent both quantitative and qualitative data. An FCM consists of some nodes/concepts which indicate the main features of the system and some edges/arcs between nodes showing the relationships between them [18]. Fig. 1 shows a simple FCM diagram with five nodes and nine weighted edges, where each node $C_{i}$ takes values in the range $A_{i} \in[0,1]$, and each edge between two nodes, $C_{i}$ and $C_{j}$, has a weight, $W_{i j}$ in the interval $[-1,1]$ which denotes the influence of each node on the others.

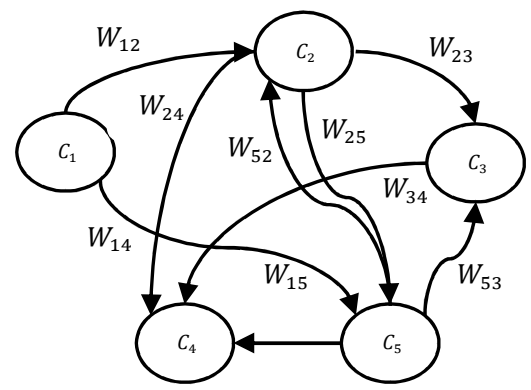

Fig. 1. A simple FCM graph.

The sign of arcs' weights $\left(+W_{i j} /-W_{i j}\right)$ states the increase/decrease between concepts in the same or opposite directions. In the other words, if an increase in concept $C_{i}$ results 
A. Jamshidi et al.

in an increase in concept $C_{j}$ (same directions), the sign of $W_{i j}$ will be positive, and vice versa. The types of concepts and dependencies among them, directions of dependencies, and initial weights of concepts and arcs are significantly based on the experience and knowledge of experts [21].

After assigning initial values to the concepts and weights, the FCM converges to a steady state through the interaction of equation (1). At each step, the value $A_{i}$ of the concept $C_{i}$ is influenced by the values of concepts connected to it and it is updated [22].

$$
A_{i}^{k+1}=f\left(A_{i}^{(k)}+\sum_{\substack{j=1 \\ j \neq i}}^{n} W_{i j} A_{j}^{(k)}\right),
$$

where,

$W_{i j}$ is the initial weight of the arc between concepts $C_{i}$ and $C_{j}$;

$A_{i}^{k+1}$ is the value of concept $C_{i}$ at step $k+1$;

$k$ stands for the iteration counter;

$f$ is a threshold or barrier function, which is used to restrict the concept value into $[0,1]$ range. Different types of threshold function $f$ could be applied in Eq. 1 depending on the concepts interval. The most common types are; tangent hyperbolic $(f(x)=\tanh (x))$, bivalent function $(\mathrm{f}(\mathrm{x})=0$ or 1$)$, sigmoid function $\left(f(x)=1 /\left(1+e^{-\lambda x}\right)\right)$, and trivalent function $(\mathrm{f}(\mathrm{x})=-1,0$ or 1$)$.

At each iteration, Eq. 1 produces a new value for the concepts and when FCM arrives at one of the following three states, the iterations end and it results in a steady state [20];

1) The value of concepts have stabilized at a fixed value (fixed equilibrium point),

2) A limited state cycle is reached,

3) Chaotic behavior has appeared.

As mentioned by Papageorgiou et al. [21], one of main drawbacks of FCMs is the potential convergence to undesired steady states. In the recent decade, several authors have tried to resolve this drawback by developing learning algorithms such as Differential Hebbian Learning [23] [24], particle swarm optimization (PSO) [21], Simulated Annealing (SA) [25], and etc. Learning algorithms can increase the efficiency and robustness of FCMs by updating the initial weight matrix ( $\left.W^{\text {Initial }}\right)$. According to Papageorgiou, the training methods are categorized in three groups; population-based, Hebbian-based, and hybrid, which is a combination of Hebbian-based and evolutionbased algorithms [26]. Since hybrid based algorithms ensure near-optimum solutions in the weights search space, in this paper we have applied hybrid based algorithm for training FCM and finding the optimal weight set of the FCM.

\section{The Proposed Method}

In order to illustrate the proposed tool, we adopted the risks identified in Li \& Liau [6] study regarding dynamic alliance. Dynamic alliance or VE is a temporary network of 
specialised individuals and independent institutes who work together and share skills and costs in order to better respond to fast changing market opportunities [6]. The identified risks are shown in Table 1 and the related FCM graph is depicted in Fig. 3. The definitions of these risks are available in study [6].

The FCM graph is depicted based on experts' opinions in order to show the dependencies and feedbacks among factors. To make the initial weight matrix $\left(W_{i j}\right)$, each expert individually determines the dependencies between concepts, using fuzzy linguistic terms such as Very High (VH), Low (L), etc. Then, the linguistic variables are aggregated and defuzzified to numerical values [21]. The initial weight matrix, is shown in Table 2.

In order to deffuzify a triangular fuzzy number $(1, \mathrm{~m}, \mathrm{u})$ the following Equation is usually applied:

$$
t=\frac{l+m+m+u}{4}
$$

Table 1. Risk factors in dynamic alliance [6].

\begin{tabular}{|c|l|c|}
\hline Risk & \multicolumn{1}{|c|}{ Sub-risks } & Index \\
\hline \multirow{4}{*}{ Market risk } & Demand fluctuation risk & $\mathrm{C} 1$ \\
\cline { 2 - 3 } & Competition risk & $\mathrm{C} 2$ \\
\cline { 2 - 3 } & Spillover effect risk & $\mathrm{C} 3$ \\
\hline Financial risk & Interest rate risk & $\mathrm{C} 4$ \\
\cline { 2 - 3 } & Exchange rate risk & $\mathrm{C} 5$ \\
\hline Natural risk & Natural risk & $\mathrm{C} 6$ \\
\hline \multirow{4}{*}{ Relational risk } & Trust risk & $\mathrm{C} 7$ \\
\cline { 2 - 3 } & Moral risk & $\mathrm{C} 8$ \\
\cline { 2 - 3 } & Motivation risk & $\mathrm{C} 9$ \\
\cline { 2 - 3 } & Communication risk & $\mathrm{C} 10$ \\
\cline { 2 - 3 } & Organization risk & $\mathrm{C} 11$ \\
\hline \multirow{3}{*}{ Operational risk } & Information sharing risk & $\mathrm{C} 12$ \\
\cline { 2 - 3 } & Information integration risk & $\mathrm{C} 13$ \\
\cline { 2 - 3 } & Information conveyance risk & $\mathrm{C} 14$ \\
\hline Political risk & Social risk & $\mathrm{C} 15$ \\
\cline { 2 - 3 } & Policy risk & $\mathrm{C} 16$ \\
\hline \multirow{5}{*}{ Competency risk } & Quality risk & $\mathrm{C} 17$ \\
\cline { 2 - 3 } & Cost risk & $\mathrm{C} 18$ \\
\cline { 2 - 3 } & Time risk & $\mathrm{C} 19$ \\
\cline { 2 - 3 } & Technologic risk & $\mathrm{C} 21$ \\
\hline \multirow{3}{*}{ Investment risk } & Investment recovery risk \\
\cline { 2 - 3 } & Investment implementation risk & \\
\hline \multirow{2}{*}{} & & $\mathrm{C}$ \\
\hline
\end{tabular}




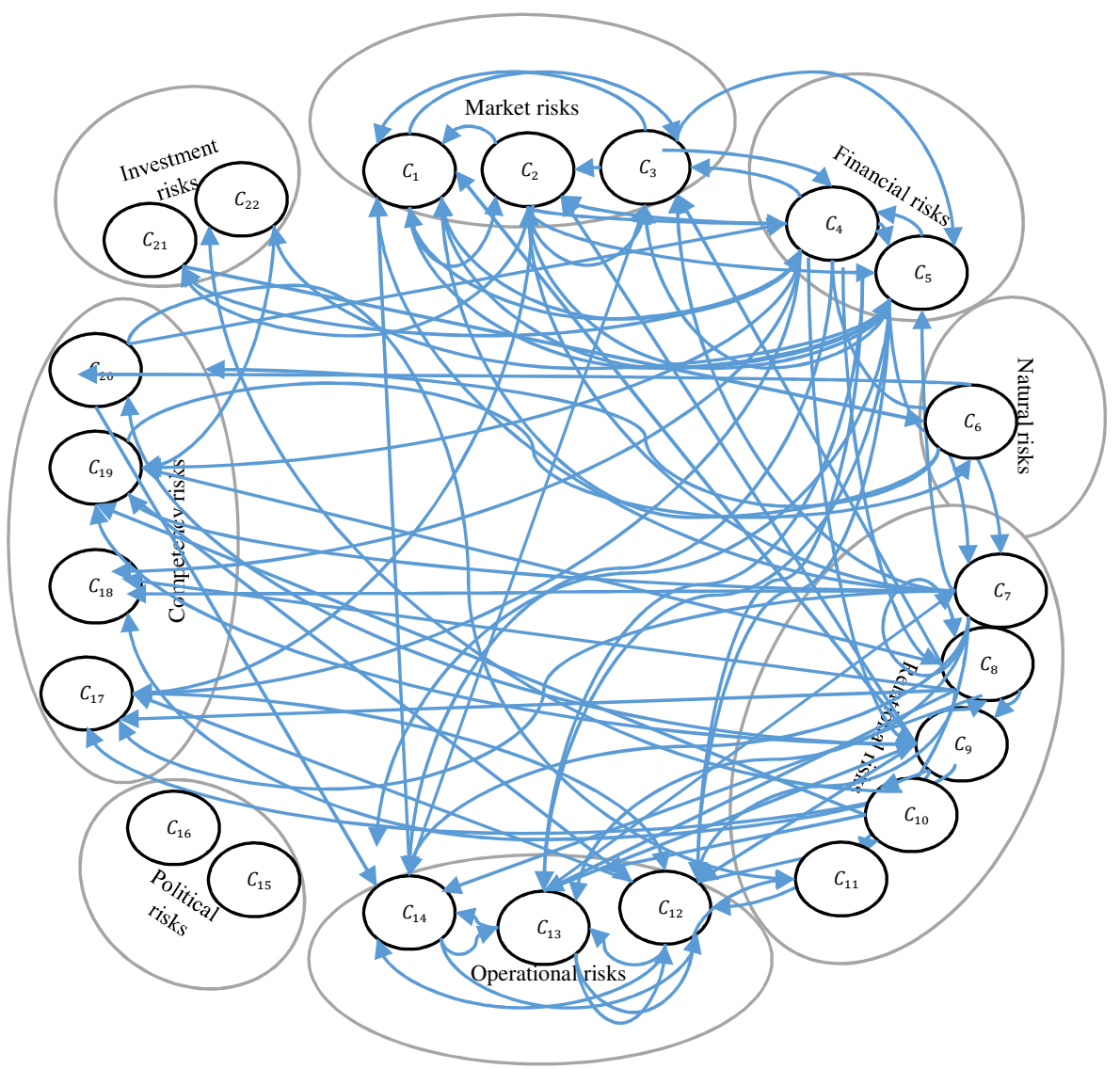

Fig. 2. FCM for risk analysis on dynamic alliance.

Table 2. Initial weight matrix.

\begin{tabular}{|c|c|c|c|c|c|c|c|c|c|c|c|c|}
\hline $\boldsymbol{W}^{\text {Aug }}$ & $\mathrm{C} 1$ & $\mathrm{C} 2$ & $\mathrm{C} 3$ & $\mathrm{C} 4$ & $\mathrm{C} 5$ &. &. & $\mathrm{C} 18$ & $\mathrm{C} 19$ & $\mathrm{C} 20$ & $\mathrm{C} 21$ & C22 \\
\hline C1 & 0 & 0.2 & 0.5 & 0 & 1 &. &. & 0 & 0 & 1 & 0 & 0.3 \\
\hline C2 & 0.2 & 0 & 0.6 & 0.5 & 0 &. &. & 0.26 & 0 & 0 & 0.1 & 0.3 \\
\hline C3 & 1 & 0 & 0 & 0 & 0 &. &. & 0 & 0 & 0.8 & 0 & 0.3 \\
\hline C4 & 0.8 & 0.9 & 0 & 0 & 0.2 &. &. & 0.12 & 0 & 0 & 0.1 & 0 \\
\hline C5 & 0.7 & 0 & 0.8 & 0.4 & 0 &. &. & 0 & 0 & 0.4 & 0 & 0 \\
\hline C6 & 0.8 & 1 & 0 & 0 & 0.2 &. &. & 0 & 0.1 & 0 & 0 & 0 \\
\hline C7 & 0.8 & 0 & 0 & 0.6 & 0.6 &. &. & 0.78 & 0 & 0 & 1 & 0.38 \\
\hline
\end{tabular}




\begin{tabular}{|c|c|c|c|c|c|c|c|c|c|c|c|c|}
\hline C8 & 0 & 0.2 & 0 & 0.5 & 0 &. &. & 0 & 0 & 0.5 & 0.1 & 0.1 \\
\hline C9 & 0.7 & 0.3 & 0.8 & 0.8 & 0.5 &. &. & 0 & 0.78 & 0 & 0.99 & 0 \\
\hline C10 & 0.1 & 0.35 & 0.2 & 0.1 & 0.9 &. &. & 0 & 0 & 0 & 0 & 0 \\
\hline C11 & 0.4 & 0 & 0.2 & 0 & 0 &. &. & 0 & 0 & 0.1 & 0.1 & 0 \\
\hline C12 & 0 & 1 & 0.1 & 0 & 0 &. &. & 0.5 & 0.3 & 0 & 0 & 0.9 \\
\hline C13 & 0 & 0.3 & 1 & 0.2 & 0 &. &. & 0 & 0 & 0.2 & 0.1 & -1 \\
\hline C14 & 0 & 0 & 0.5 & 0.5 & 0 &. &. & 0 & 0.6 & 0 & 0 & 0.8 \\
\hline C15 & 0.7 & 0.3 & 0.3 & 0 & 0.9 &. &. & 0 & 0 & 0 & 0.6 & 0.9 \\
\hline C16 & 0.2 & 0 & 0.1 & 0 & 0 &. &. & 1 & 0.67 & 0 & 0 & 0 \\
\hline C17 & 0.65 & 0.3 & 0 & 0.8 & 0.5 &. &. & 0 & 0 & 0.3 & 0.1 & 0 \\
\hline C18 & 0.7 & 0 & 0 & 0 & 0.1 &. &. & 0 & 0.6 & 0 & 0.5 & 0 \\
\hline C19 & 0.2 & 0.5 & 0 & 0.8 & 0 &. &. & 0.3 & 0 & 0 & 0.1 & 0 \\
\hline C20 & 0.6 & 0 & 0.3 & 0 & 0 &. &. & 0.9 & 0.7 & 0 & 0.1 & 0.56 \\
\hline C21 & 0 & 0.6 & 0.7 & 0 & 0 &. &. & 0.3 & 0.2 & 0.1 & 0 & 0.8 \\
\hline C22 & 0 & 0 & 1 & 0.5 & 0 &. &. & 0 & 0.7 & 0.1 & 0.5 & 0 \\
\hline
\end{tabular}

\section{FCM Building Process}

Two types of FCM model could be developed for evaluating risks. The first type is scenario-based which is used in this paper and the second type is based on initial concept values obtained from multi criteria decision making tools such as AHP/ANP or eigenvalue approach. Scenario-based FCM is a new method recently presented by different authors and it is becoming popular in complex and fast-changing domains such as business environment, therefore it is critical to predict the impact of potential risks that could be happened in the future. In order to evaluate the impact of risks in a scenariobased FCM model, several what-if analysis scenarios should be developed using different initial concept values $(c)$. In each scenario, a risk or a set of risks are activated and using Eq. 1 and using learning algorithms the initial vector $(c)$ is updated in order to show the impact of activated risks on the other risks. Note that when a risk is activated, its value in the initial vector $(c)$ is considered 1 . This number is 0 for the rest of the risk factors which are not activated.

In second type of FCM modeling, the initial concept values $(c)$ is updated by using initial weight matrix $\left(W_{i j}\right)$ and Eq. 1 until it converges to the steady state condition. The updated concept values $C^{*}$ shows the importance of each risk. Since this type of FCM is unable to assess the impact of each risk on the other risks, we propose to apply the first type in evaluating the risk of CNs. To illustrate the risk evaluation process, in this paper we only assess the impact of "Market risks" on other risks.

In this scenario, at the initial time only risks related to market risks including "Demand fluctuation risk (C1)", "Competition risk (C2)", and "Spillover effect risk (C3)" are activated. 
$c=[\mathbf{1}, \mathbf{1}, \mathbf{1}, 0,0,0,0,0,0,0,0,0,0,0,0,0,0,0,0,0,0,0]$

Using $W_{i j}$ matrix, Initial concept vector $c$, Equation (1) and learning algorithm, the training process starts. In this paper we applied NHL-DE algorithm for training FCM which is a combination of nonlinear Hebbian learning (NHL) and differential evolution (DE) algorithms. According to Papageorgiou [27], the hybrid training approaches such as NHL-DE emerge less limitations as they combine two training algorithms and inherit the benefits and shortcomings of both of them. The training process in NHL-DE has two steps. The first step starts with NHL algorithm and in the second step, the result of first step is used to seed the DE algorithm. We imported the data into Matlab code and we used MATLAB version R2012a software to obtain the updated concept matrix $\left(C^{*}\right)$. In this paper, the values of learning rate parameter $(\eta)$, mutation constant $(\mu)$, crossover constant (CR), and weight decay learning parameter $(\gamma)$ have been selected $0.04,0.5,0.5,0.98$ respectively. The population size is considered 50. It should be noted we performed 1000 iterations for the algorithm per experiment and 100 independent experiments were performed.

$C^{*}=[0.7,0.47,0.85,0.7, \underline{\mathbf{0 . 9 8}}, 0.4,0, \underline{\mathbf{0 . 9 4}}, 0, \underline{\mathbf{0 . 9 7}}, 0.2,0.49,0.78,0.21, \underline{\mathbf{0 . 9 3}}, 0.7$,

$\underline{\mathbf{0 . 9 1}}, 0.1,0.78, \underline{\mathbf{0 . 9 9}}, 0,0.37]$;

The steady state vector $C^{*}$ shows that activating $\mathrm{C} 1, \mathrm{C} 2$, and $\mathrm{C} 3$ risks have a strong influence over the remainder risks in particular risks C5, C8, C10, C15, C17, and C20.

The same procedure should be done for all other risks by activating their sub-risks each time. The results reveals that which risks are critical. In addition, the proposed tool is able to predict the impact of each risk on the other risks more accurately because it take into account the multiple connections between risks. Therefore, decision makers will be able to manage the risks of CNs properly and accurately. It should be noted that the process for developing a FCM is strongly dependent on the experts' opinions. Then, special attention should be paid to matters such as the selection of experts' team and the feedback with them.

\section{Conclusion}

This paper proposes an advanced decision support tool called "Fuzzy Cognitive Maps" (FCM) which can deal with risks of collaborative networks by taking into account the interrelationships among factors. This tool can be adapted to a wide range of multi criteria decision making problems such as predicting behaviors in CNs, partner selection, policy analysis, modeling collaboration preparedness assessment, etc.

The main features of FCM in contrast with those of other existing methods are; 1) the relationships among variety of factors and also importance of factors could be considered 
,2) uncertainties and imprecise information are taken into account on the decision-making process, 3) several experts can state their opinions, 4) it has capabilities to handle both qualitative and quantitative factors, 5) several alternatives can be considered in decision making about best partner and 6) by using the casual graphs in FCM, it is easier for decision makers and experts to understand the factors and their dependencies. Moreover, by relying on FCM models, the decision makers have a strong support, and therefore are able to decide more precisely and accurately when evaluating risks or choosing the partner. As a future research topic, application of other hybrid algorithms for training FCM could be considered. Currently, we are working on developing a comprehensive framework for partner selection problem in dynamic alliance by using an integrated FCMbased method.

Acknowledgements. This research was partially financed by grants [OPG 0293307 and OPG 0118062] from the Canadian Natural Sciences and Engineering Research Council (NSERC). This support is gratefully acknowledged.

\section{References}

1. T. P. Munyon and A. A. Perryman, "The Dynamics of Effective Organization Alliances," Organizational Dynamics, vol. 40, pp. 96-103, 2011.

2. H. Hexin and C. Jim, "A Partner Selection Method Based on Risk Evaluation in Virtual Enterprises," in Proceedings of ICSSSM (International Conference on Services Systems and Services Management), 2005.

3. R. H.Shah and A. Nathan, "Factors influencing partner selection in strategic alliances: the moderating role of alliance context," Strategic Management Journal, 29, pp. 471-494, 2008.

4. T. Jarimo and A. Salo, "Optimal Partner Selection in Virtual Organisations With Capacity Risk and Network Interdependencies," IEEE Journal of Systems, Man, Cybernetics , 2007.

5. J. Rosas and L. M. Camarinha-Matos, "Modeling collaboration preparedness assessment," in Collaborative Networks: Reference Modeling, Lisbon, Springer, 2008, pp. 227-252.

6. Y. LI and X. Liao, "Decision support for risk analysis on dynamic alliance," Decision support systems, vol. 42, p. 2043-2059, 2007.

7. X. Zhou and M. Lu, "Risk Evaluation of Dynamic Alliance Based on Fuzzy Analytic Network Process and Fuzzy TOPSIS," J. Service Science and Management, vol. 5, pp. 230-240, 2012.

8. T. K. Das and B. S. Teng, "A Risk Perception Model of Alliance Structuring," Journal of International Management, vol. 7, no. 1, pp. 1-29, 2001.

9. W. H. Ip, M. Huang, K. L. Yung and D. W. Wang, "Genetic Algorithm Solution for a RiskBased Partner Selection Problem in a Virtual Enterprise," Computers \& Operations Research, vol. 30, no. 2, pp. 213-231, 2003.

10. M. Huang, W. H. Ip, H. M. Yang, X. W. Wang and H. C. W. Lau, "A Fuzzy Synthetic Evaluation Embedded Tabu Search for Risk Programming of Virtual Enterprises," International Journal of Production Economics, vol. 116, no. 1, pp. 104-114, 2008.

11. M. Huang, F. Q. Lu, W. K. Ching and T. K. Siu, "A Distributed Decision Making Model for Risk Management of Virtual Enterprise," Expert Systems with Applications, vol. 38, no. 10, pp. 13208-13215, 2011. 
12. G. T. R. Yu, "A soft computing method for multi-criteria decision making with dependence and feedback," Applied Mathematics and Computation , vol. 180, pp. 63-75, 2006.

13. B. Kosko, "Fuzzy cognitive maps," Int J Man-Machine Studies, vol. 24, p. 65-75, 1986.

14. C. Lopez and J. L. Salmeron, "Dynamic risks modelling in ERP maintenance projects with FCM," Information Sciences, vol. 256, p. 25-45, 2014.

15. K. Ahmad and A. Kumar, "Forecasting Risk and Risk Consequences on ERP Maintenance," International Journal of Soft Computing and Engineering, vol. 2, no. 5, pp. 13-18, 2012.

16. J. L. Salmeron, "Fuzzy Cognitive Maps-Based IT Projects Risks Scenarios," Studies in Fuzziness and Soft Computing, vol. 247, pp. 201-215, 2010.

17. B. Kosko, "Fuzzy cognitive maps," Int. J. Man. Mach. Stud., vol. 24, pp. 65-75, 1986.

18. W. C. L. L. Zhi Xiao, "An integrated FCM and fuzzy soft set for supplier selection problem based on risk evaluation," Applied Mathematical Modelling, vol. 36, pp. 1444-1454, 2012.

19. M. Glykas , Fuzzy Cognitive Maps, Advances in Theory, Methodologies, Tools and Applications, Greece: Springer, 2010.

20. E. I. Papageorgiou, Fuzzy Cognitive Maps for Applied Sciences and Engineering (From Fundamentals to Extensions and Learning Algorithms), Springer, 2014.

21. K. E. P. C. S. S. P. P. G. M. N. V. Elpiniki I. Papageorgiou, "Fuzzy Cognitive Maps Learning Using Particle Swarm Optimization," Intelligent Information Systems, 25(1), pp. 95-121, 2005.

22. B. Kosko, Fuzzy Engineering, NewYork: Prentice Hall, 1997.

23. C. S. P. G. E.I. Papageorgiou, "Active Hebbian learning algorithm to train fuzzy cognitive maps," International Journal of Approximate Reasoning, vol. 37, pp. 219-249, 2004.

24. A. P. D. K. a. V. T. G.A. Papakostas, "Training Fuzzy Cognitive Maps by Using Hebbian Learning Algorithms: A Comparative Study," in IEEE International Conference on Fuzzy Systems, Taipei, Taiwan, 2011.

25. M. G. Somayeh Alizadeh, "Learning FCM by chaotic simulated annealing," Chaos, Solitons and Fractals, vol. 41, pp. 1182-1190, 2009.

26. E. Papageorgiou, " Learning algorithms for fuzzy cognitive maps: a review study," IEEE Transactions, vol. 42, no. 2, p. 150-163, 2012.

27. E. I. Papageorgiou, Fuzzy Cognitive Maps for Applied Sciences and Engineering, Greece: Springer, 2014.

28. E. I. Papageorgiou and P. P. Groumpos, "A new hybrid method using evolutionary algorithms to train Fuzzy Cognitive Maps," Applied Soft Computing, vol. 5, pp. 409-431, 2005.

29. R. C. Basole and M. A. Bellamy, "Visual analysis of supply network risks: Insights from the electronics industry," Decision Support Systems, vol. 67, p. 109-120, 2014.

30. H. Gou, B. Huang, W. Liu and X. Li, "A framework for virtual enterprise operation management," Computers in Industry, vol. 50, p. 333 - 352, 2003.

31. H. Delerue and E. Simon, "National Cultural Values and the Perceived Relational Risks in Biotechnology Alliance Relationships," International Business Review, 18(1), pp. 14-25, 2009.

32. A. Jamshidi, S. Abbasgholizadeh Rahimi, D. Ait-Kadi and A. Ruiz, "A comprehensive fuzzy risk-based maintenance framework for prioritization of medical devices," Applied Soft Computing, vol. 32, p. 322-334, 2015.

33. Jamshidi, S. Abbasgholizadeh Rahimi, D. Ait Kadi and A. R. , "Using Fuzzy Cost-Based FMEA, GRA and Profitability Theory for Minimizing Failures at a Healthcare Diagnosis Service," Quality and Reliability Engineering, vol. 31, no. 4, pp. 601-615, 2013.

34. Jamshidi, S. Abasgholizadeh Rahimi , A. Ruiz and D. Ait-Kadi, "A new framework for risk assessment in ERP maintenance," in Reliability and Maintainability Symposium (RAMS), Annual, Colorado Springs, 2014. 